\title{
An editor departs
}

Roy Meadow joined Roger Robinson as coeditor of The Archives of Disease in Childhood in 1979. This month he retires from office having been senior editor for five years.

During the past nine years the number of original papers submitted has increased from about 450 to 850 each year and the total number of manuscripts to over 1000 . The number of pages published has risen from about 1000 to 1300 each year. The publication time has fallen from 14 months to about four months due to a policy of accepting a ration of papers which would fill the space available. Another innovation was an increase in the number of commissioned articles. This has provided a background for the general reader and enabled the editors to accept sound, specialised, original work of limited appeal.

Before Roy Meadow became editor there were about nine annotations, two editorials, and four other similar articles a year: and now there are about 30 annotations, three editorials, and 24 personal practice or current topic papers. Some cosmetic surgery and a little colour added to the cover have provided the extra space needed for the larger number of titles. The Diamond Jubilee edition last year was his idea, and was published despite many obstacles. Instead of providing a conventional history of the Journal he devised new ways to interest writers in history and to capture the reader's eye.

While he was increasing the scope and quality of the Journal, other aspects of Roy's professional life expanded enormously. When he was appointed editor in 1979 he was a senior lecturer and the following year was appointed inaugural professor and head of the department of paediatrics and child health at St James's Hospital in Leeds. He had the task of developing a new university paediatric department during a period of financial stringency. He maintained his extensive research in nephrology, enuresis, and Munchausen by proxy, which is now known universally as Meadow's syndrome. His descriptions of this syndrome showed his ability to detect the vital fact within the mire of collected trivia and confirmed that bedside research was still alive.

His boundless enthusiasm for writing did not diminish, and the fifth edition of his popular undergraduate book Notes on Paediatrics was published in 1986. Two other books have been pub-

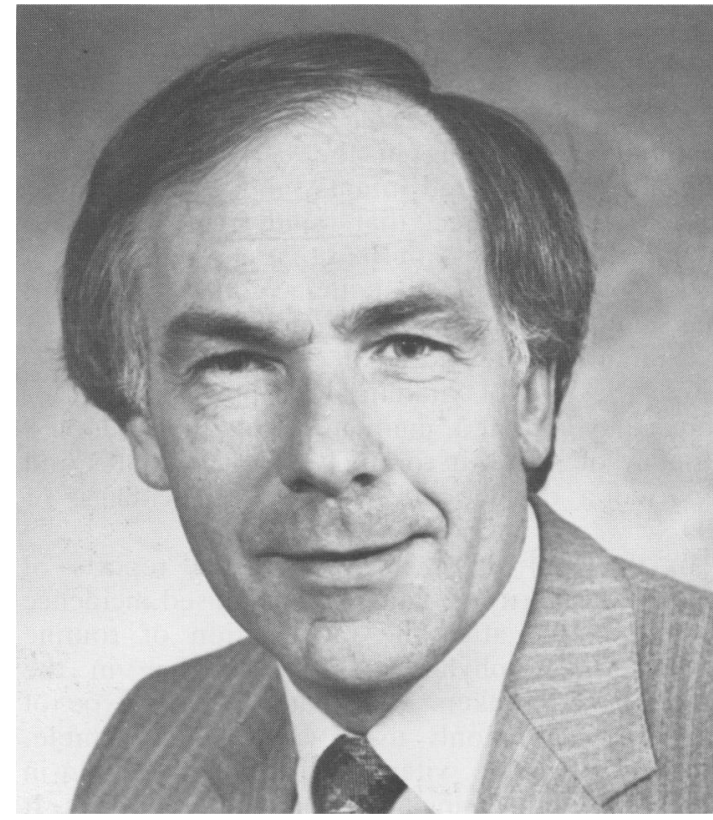

lished since 1979, and a new book on paediatric kidney disease will be published this year. He has been editor of two editions of Recent Advances in Paediatrics, which has now become an essential part of every paediatrician's home library. Roy also generously provided nine chapters for editors of other books. He has been an examiner for the final MB in seven universities, chairman of the Association for Child Psychology and Psychiatry, and a member of his District Health Authority, a post which has caused more frustration than all the rest put together.

Despite all these pressures on his time he has always put the work of The Archives first. When he was phoned at home over the weekend or during the evening he was always available to give a coeditor wise advice at those moments when a problem seemed insoluble. He had the knack of choosing the perceptive referee who was able to improve the quality of the paper by constructive criticism.

We thank Roy for the nine years of hard labour he devoted to the Journal which flourished under his guidance, and we wish him many more years of productive writing. 